А. А. Тимочко

Лётная академия Национального авиационного университета, Кропивницкий, Украина

\title{
РАЗРАБОТКА БАЗЫ НЕЧЕТКИХ ПРОДУКЦИОННЫХ ПРАВИЛ НЕЧЕТКОЙ ЛОГИЧЕСКОЙ СИСТЕМЫ КЛАССИФИКАЦИИ ВОЗДУШНЫХ ОБЪЕКТОВ В ПРОЦЕССЕ КОНТРОЛЯ ВОЗДУШНОГО ПРОСТРАНСТВА И ОБОБЩЕННОГО АЛГОРИТМА ИХ РЕАЛИЗАЦИИ
}

\begin{abstract}
Контроль воздушного пространства требует создания системы классификации воздушных объектов. Данная задача решается в нечеткой постановке. Для этого разработана база нечетких продукционных правил и обобщенный алгоритм их реализации. Утверждается, что традиционные подходы к разработке баз правил не достаточно эффективны для рассматриваемой предметной области. Цель статьи - разработка базы нечетких продукционных правил нечеткой логической системы классификации воздушных объектов. Проанализированы подходы к разработке базы нечетких продукционных правил нечетких логических систем классификации. Для классификации воздушного объекта устанавливается его принадлежность к наперед заданному классу. Наперед заданные классы формально задаются в виде множества. Элементами множества являются классы, определяемые автоматически или задаваемые автоматизировано. Определены основные признаки для классификации воздушных объектов. Значения признаков определяются по результатам обобщения трассовой информации или устанавливаются по умолчанию. Значения признаков представляют собой лингвистические переменные. В общем случае они являются нечеткими числами, описывающими термы соответствующих лингвистических переменных. Структурно нечеткие продукционные правила соответствуют правилам нечеткой логической модели Сугэно 0-го порядка. Разработан пример использования нечеткого логического вывода Сугэно 0-го порядка на базе разработанных правил. Разработанная база нечетких продукционных правил и обобщенный алгоритм их реализации являются основой метода верификации программного обеспечения нечеткой логической системы классификации воздушных объектов в процессе контроля воздушного пространства.
\end{abstract}

Ключевые слова: нечеткое продукционное правило, классификация воздушных объектов, база знаний, функция принадлежности, признак воздушного объекта.

\section{Введение}

Постановка проблемы. При разработке метода верификации программного обеспечения нечеткой логической системы классификации воздушных объектов при контроле воздушного пространства остро стоит проблема создания базы нечетких продукционных правил нечеткой логической системы.

С одной стороны, необходимо предложить классификацию исследуемых воздушных объектов (ВОб). Для этого необходимо описать каждый класс ВОб в процессе контроля воздушного пространства определенным количеством признаков. С другой стороны, необходимо определить их значения, которые представляют собой лингвистические переменные (ЛП) в терминах нечетких множеств.

Таким образом, для разработки метода верификации программного продукта нечеткой логической системы классификации воздушных объектов при контроле воздушного пространства необходимо разработать соответствующую базу нечетких продукционных правил.

Цель статьи - разработка базы нечетких продукционных правил нечеткой логической системы классификации воздушных объектов.

Анализ литературы. Рассмотрим основные работы в области теории и практики построения баз правил для нечетких логических систем классификации ВОб в ходе воздушного пространства.

Так, в работах $[1,2]$ рассматриваются некоторые специфические вопросы построения сетевых моделей и процедур логического вывода. Анализ работ показал, что искусственное ограничение учета нечеткости уменьшает возможности моделирования.
В работе [3] рассматривается устойчивость решений для задач нечеткого управления в системах классификации при учете взаимодействия динамических нечетких процессов. В работе [4] исследуется влияние конфликтности, наличия ошибок и избыточности в базах знаний на эффективность решений. В работе [5] для верификации программного продукта нечеткой логической системы классификации доказывается возможность представления процессов в пространстве состояний нечеткой раскрашенной сетью Петри. В работе [6] рассматривается процесс формирования продукционных правил определения целесообразных параметров перехвата воздушных целей в условиях нестохастической неопределенности. Таким образом, с одной стороны, известные подходы к построению баз нечетких правил не позволяют их напрямую применять для рассматриваемой предметной области. С другой стороны, для обобщенного алгоритма реализации нечетких продукционных правил классификации объектов необходимо при помощи соответствующих характеристик их описать количественно и качественно.

Поэтому представляется необходимым разработка новых нечетких продукционных правил классификации воздушных объектов, свободных от указанных выше недостатков и позволяющих разработать метод верификации программного обеспечения нечеткой логической системы классификации.

\section{Изложение основного материала}

Процесс классификации воздушных объектов (ВОб) рассматривается как установление принадлежности конкретного рассматриваемого ВОб $x \in X$ к наперед заданному классу ВОб: 


$$
F: X \rightarrow\left\{K_{i}^{A O}\right\}
$$

где $X$ - множество всех выявленных ВОб; $x$ - ВОб с номером $N_{l}^{A O}, l=\overline{1, L}, L-$ количество выявленных ВОб; $K_{i}^{A O}-$ класс ВОб, $i=\overline{1,10}$.

Формально наперед заданные классы ВОб задаются в виде множества $\left\{K_{i}^{A O}\right\}$, элементами которого являются классы, определяемые так:

1) классы, определяемые автоматически или задаваемые автоматизировано:

$K_{1}^{A O}$ "ВОб неопределенный";

$K_{2}^{A O}$ "ВОб - самолет по заявке";

$K_{3}^{A O}$ "ВОб - нарушитель режима полетов";

$K_{4}^{A O}$ "ВОб без сигнала опознавания";

$K_{5}^{A O}$ "ВОб с сигналом опознавания";

$K_{6}^{A O} \quad$ "ВОб постановщик помех";

2) классы, задаваемые автоматизировано:

$K_{7}^{A O}$ "ВОб - свой самолет госавиации";

$K_{8}^{A O}$ "ВОб - контрольный самолет";

$K_{9}^{A O}$ "ВОб - иностранный самолет - нарушитель государственной границы";

$K_{10}^{A O}$ "ВОб - воздушный противник".

Значения множества характеристик ВОб $\left\{c_{j}^{A O}\right\}$ и классы ВОб множества $\left\{K_{i}^{A O}\right\}$ находятся между собой в бинарном отношении с матрицей

$$
\rho=\left[d_{j i}\right]_{m \times n},
$$

где $d_{j i}=1$, если $c_{j}^{A O} \in K_{i}^{A O}$, а иначе $d_{j i}=0 ; m-$ количество значений характеристик ВОб; $n$ - количество классов ВОб. Признаки ВОб, рассматриваемые как элементы множества $\left\{c_{j}^{A O}\right\}$, для классификации ВОб: определения государственной принадлежности (ОГП) $c_{1}^{A O}$; корреляции план-трека $c_{2}^{A O}$; нарушения режима полетов $c_{3}^{A O}$; сопровождения траектории триангуляционным методом $c_{4}^{A O}$.

Значения признаков $c_{1}^{A O}, c_{2}^{A O}, c_{4}^{A O}$ определяются по результатам обобщения трассовой информации о ВОб и представляют собой ЛП в терминах нечетких множеств.

Если нет нарушения, то значение признака $c_{3}^{A O}$ по умолчанию равно 0, и автоматически изменяется на 1 при нарушении, если введен тип нарушения режима полетов для соответствующего ВОб.

Значения признаков $c_{1}^{A O}, c_{2}^{A O}, c_{4}^{A O}$, и $c_{3}^{A O}$, в общем случае, являются нечеткими числами, описывающими термы соответствующих ЛП (рис. 1).

Автоматическая классификация выполняется по следующим лингвистически описанным правилам:
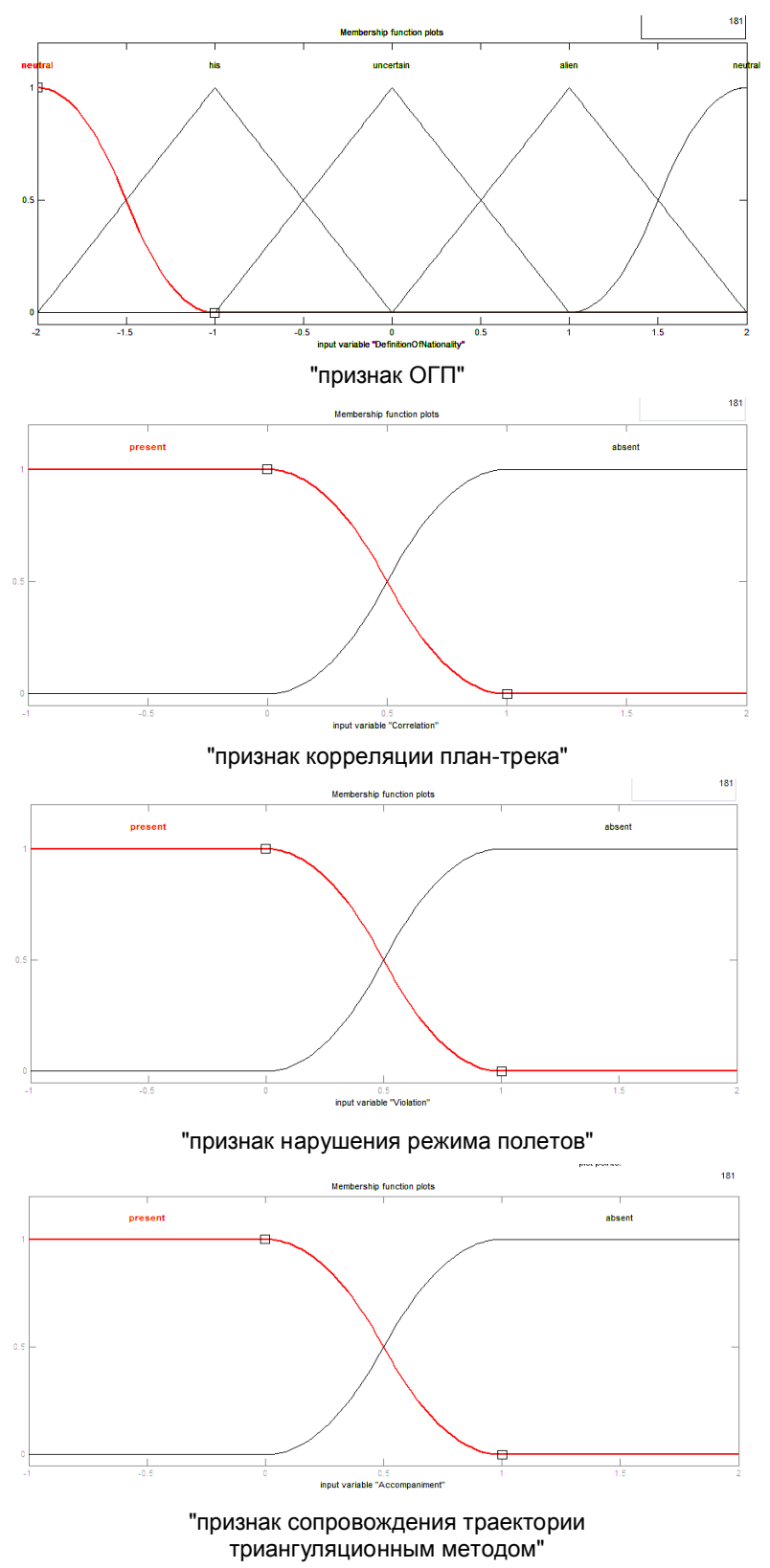

Рис. 1. Функции принадлежностей термов ЛП

- класс "неопределенный ВОб" присваивается автоматически тем ВОб, у которых признак опознавания государственной принадлежности (ОГП) не определен (ВОб не запрошен системой радиолокационного опознавания);

- класс "ВОб - самолет по заявке" присваивается автоматически тем ВОб, которые не нарушают установленного режима полетов и для которых есть корреляция "план-трек";

- класс "ВОб - нарушитель режима полетов" присваивается автоматически тем ВОб, которые нарушают установленный режим полетов и для которых есть корреляция "план-трек", предварительная фиксация нарушения осуществляется автоматизировано путем ввода нарушения рассматриваемого ВОб;

- класс "ВОб без сигнала опознавания" присваивается автоматически тем ВОб, для которых нет корреляции "план-трек" и признак ОГП имеет значение "чужой"; 
- класс "ВОб с сигналом опознавания" присваивается автоматически тем ВОб, для которых нет корреляции "план-трек" и признак ОГП имеет значение "свой" или "нейтральный";

- класс "ВОб постановщик помех" присваивается автоматически тем ВОб, для которых нет корреляции «план-трек», признак ОГП имеет значение "чужой" и траектория полета обрабатывается с использованием триангуляционного метода.

Автоматизированный режим позволяет изменить оператору принадлежность ВОб к классам из предыдущего перечня, определенную в результате автоматической классификации, а также установить или изменить принадлежность ВОб к следующим классам, согласно выше описанных правил, дополненных следующими:

- класс "ВОб - свой самолет государственной авиации" присваивается автоматизировано по решению оператора (признак ОГП которых имеет значение "свой") после определения оператором факта взлета самолета, обнаружения и захвата его на сопровождение и по результатам оценки воздушной обстановки, отображаемой на средствах отображения индивидуального и коллективного пользования;

- класс "ВОб - контрольный самолет" присваивается автоматизировано по решению оператора тем ВОб, которые являются своими самолетами (признак ОГП имеет значение "свой") и вылетели для обозначения воздушного противника на учениях, тренировках, проверках боевой готовности;

- класс "ВОб - иностранный самолет - нарушитель государственной границы" присваивается автоматизировано по решению оператора тем ВОб, для которых нет корреляции "план-трек", которые являются иностранными самолетами, и для которых выявлен факт пересечения государственной границы;

- класс "ВОб - воздушный противник" присваивается автоматизировано по решению оператора, исходя из складывающейся воздушной обстановки в зоне ответственности, у которых признак ОГП имеет значение "чужой".

Формально правила классификации ВОб, определяющие матрицу отношений 2 , задаются совокупностью таких нечетких продукционных правил:

$$
\begin{aligned}
& \text { IF } c_{1}^{A O}=00 \text { THEN } x=K_{1}^{A O} \text {; } \\
& \text { IF } c_{3}^{A O}=0 \text { AND } c_{2}^{A O}=1 \text { THEN } x=K_{2}^{A O} \text {; } \\
& I F c_{3}^{A O}=1 A N D c_{2}^{A O}=1 T H E N x=K_{3}^{A O} \text {; } \\
& I F c_{1}^{A O}=01 A N D c_{2}^{A O}=0 \text { THEN } x=K_{4}^{A O} \text {; } \\
& \operatorname{IF}\left(c_{1}^{A O}=10 O R c_{1}^{A O}=11\right) A N D c_{2}^{A O}=0 \text { THEN } x=K_{5}^{A O} ;(7) \\
& I F c_{1}^{A O}=01 A N D c_{2}^{A O}=0 A N D c_{4}^{A O}=1 T H E N x=K_{6}^{A O} \text {; } \\
& I F c_{1}^{A O}=10 A N D O^{d}=o_{1}^{d} \text { THEN } x=K_{7}^{A O} \text {; } \\
& I F c_{1}^{A O}=10 A N D O^{d}=o_{2}^{d} \text { THEN } x=K_{8}^{A O} \text {; } \\
& I F c_{1}^{A O}=10 A N D c_{2}^{A O}=0 A N D O^{d}=o_{3}^{d} \text { THEN } x=K_{9}^{A O} ;(1) \\
& \text { IF } c_{1}^{A O}=01 A N D O^{d}=o_{4}^{d} \text { THEN } x=K_{10}^{A O} \text {, }
\end{aligned}
$$

где $O^{d}$ - признак действия оператора по анализу информации, необходимой для автоматизированной классификации ВОб; $o_{1}^{d}$ - определение факта взлета своего самолета, обнаружения и захвата его на сопровождение и принятие решения оператором о классе ВОб как "ВОб - свой самолет государственной авиации"; $o_{2}^{d}$ - определение факта взлета, обнаружения и захвата на сопровождение самолета для обозначения воздушного противника на учениях и принятие решения оператором как "ВОб - контрольный самолет"; $o_{3}^{d}$ - определение факта пересечения иностранным самолетом государственной границы и принятие решения оператором о классе ВОб как "ВОб - иностранный самолет - нарушитель государственной границы"; $o_{4}^{d}-$ принятие решения оператором о классе ВОб как "ВОб - воздушный противник", исходя из складывающейся воздушной обстановки.

В общем случае, значения признака действия оператора $O^{d}$ представляет собой нечеткие числа, описывающие термы соответствующей ЛП (рис. 2).

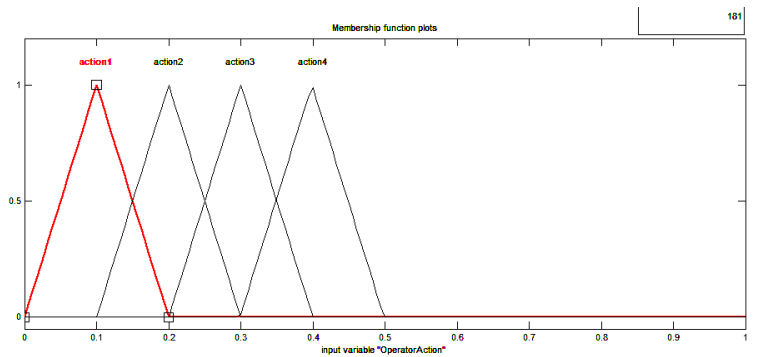

Рис. 2. Функции принадлежностей термов ЛП "признак действия оператора по анализу информации, необходимой для автоматизированной классификации ВОб, и действия по фиксации принятого им решения"

Непосредственно обобщенный алгоритм реализации нечетких продукционных правил классификации ВОб включает алгоритмы решения частных задач автоматической и автоматизированной классификации ВОб по их характеристикам на основе использования механизмов нечеткого логического вывода Сугэно 0-го порядка. Пример использования нечеткого логического вывода Сугэно 0-го порядка на базе правил (3) - (12) приведен на рис. 3, а алгоритм решения частной задачи автоматической классификации ВОб - на рис. 4.
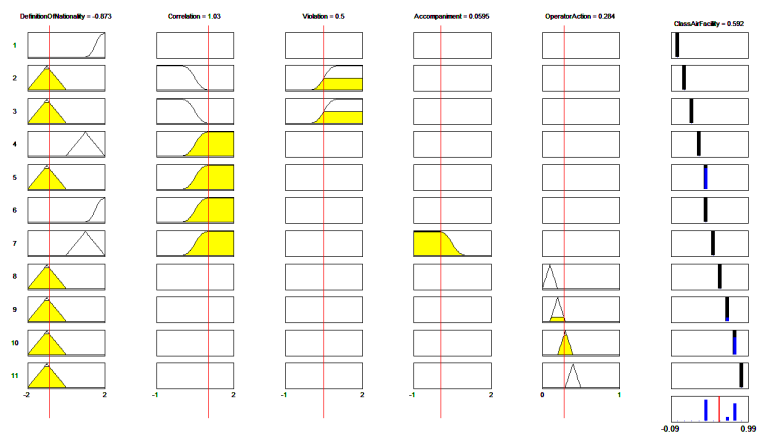

Рис. 3. Пример использования нечеткого логического вывода Сугэно 0-го порядка на базе правил нечеткой логической системы классификации воздушных объектов 


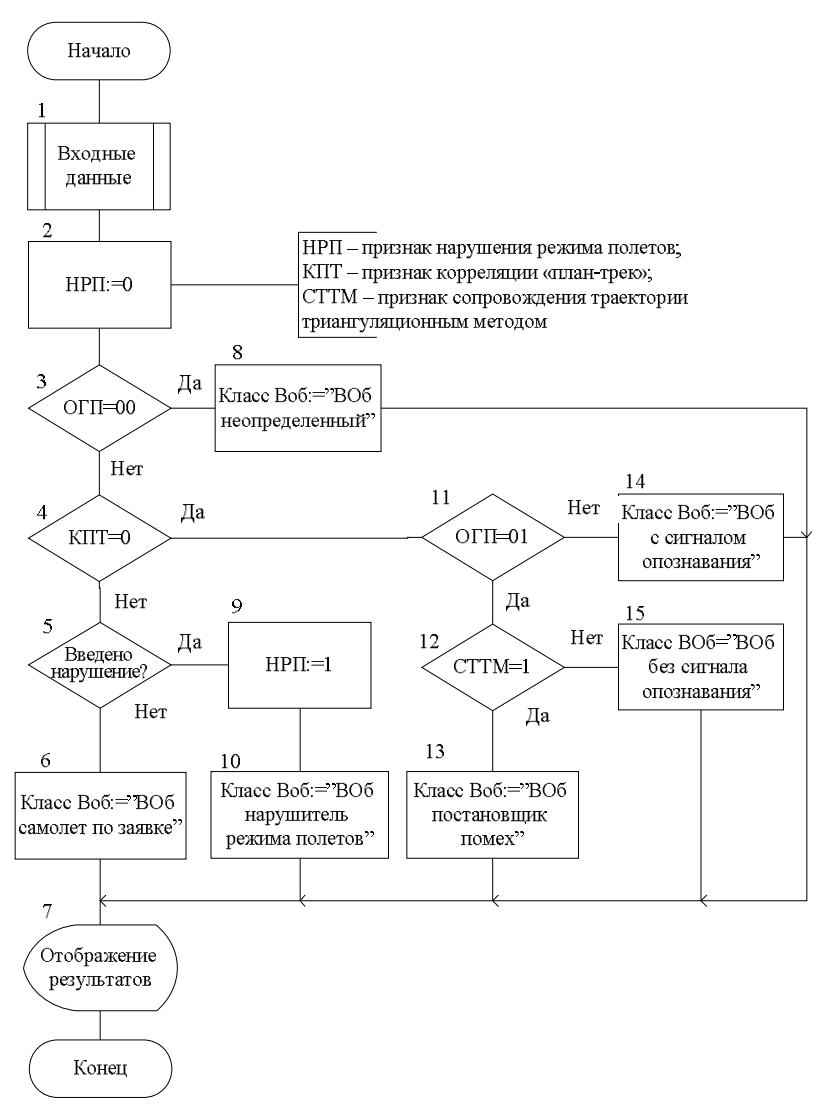

Рис. 4. Алгоритм решения частной задачи автоматической классификации ВОб

Выполнение алгоритма, реализующего нечеткие продукционные правила классификации ВОб (38), включает следующие операции и действия: поступает признак о ВОб по результатам обобщения трассовой информации (блок 1); для рассматриваемого ВОб признак нарушения режима полетов по умолчанию устанавливается в 0 (нет нарушения) (блок 2); анализируется значения признака ОГП (блок 3); если признак ОГП не определен, то ВОб классифицируется как ВОб неопределенный (блок 8); если признак ОГП определен, то анализируется значение признака корреляции «план-трек» (блок 4); если корреляции план-трека нет, то проверяется введение для ВОб нарушения режима полетов оператором (блок 6); если нарушение введено оператором, то ВОб классифицируется как ВОб нарушитель режима полетов (блок 10); если нарушение не введено оператором, то ВОб классифицируется как ВОб самолет по заявке (блок 6); если корреляции план-трека есть, то анализируется признак ОГП (блок 11); если ОГП имеет значение "01" ("чужой"), то анализируется признак сопровождения траектории ВОб триангуляционным методом (блок 12); если сопровождение траектории ВОб триангуляционным методом есть, то ВОб классифицируется как ВОб постановщик помех (блок 13); если ОГП не имеет значение "01" ("чужой"), то ВОб классифицируется как ВОб с сигналом опознавания (блок 14); результаты классификации ВОб отображаются на мониторе АРМ оператора ведения ВО (блок 7).

Алгоритм решения частной задачи автоматизированной классификации ВОб представлен на рис. 5.

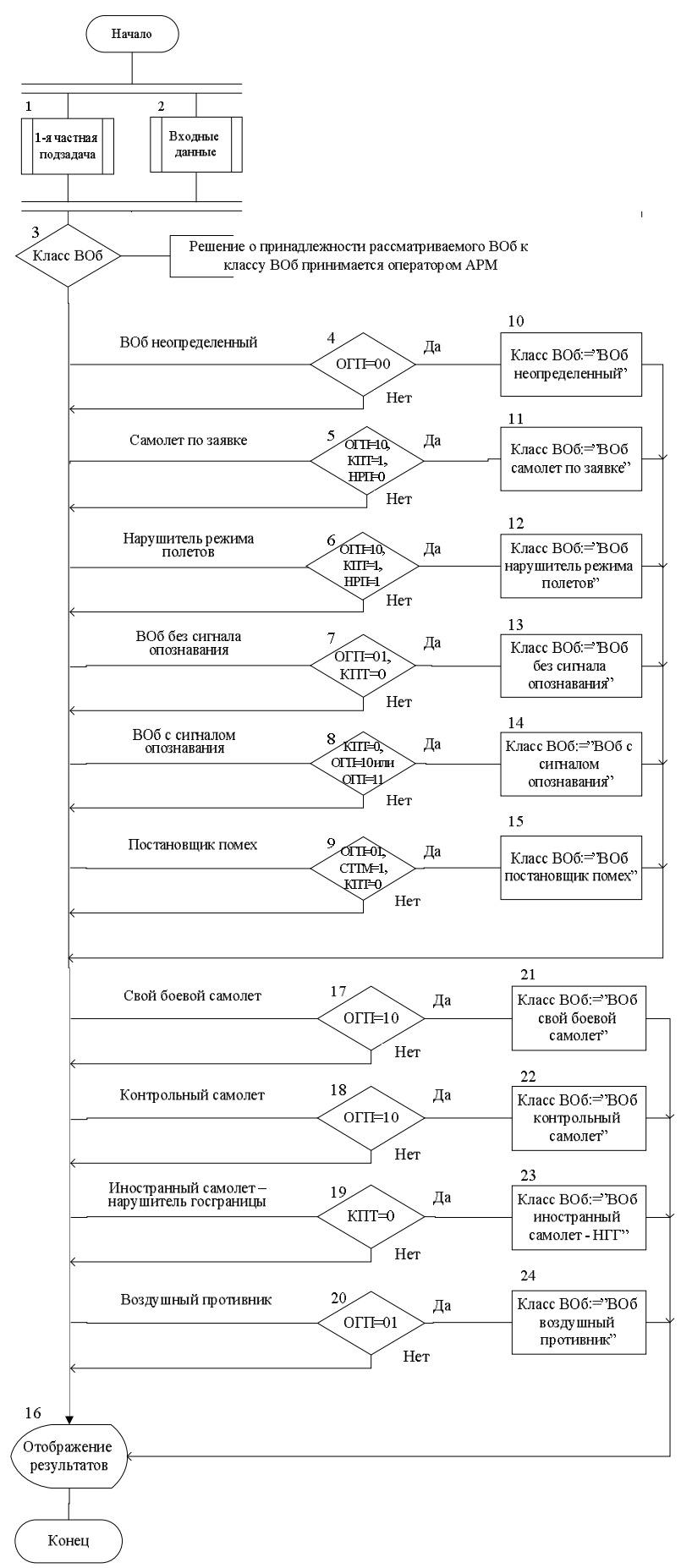

Рис. 5. Алгоритм решения частной задачи автоматизированной классификации ВОб

Выполнение алгоритма, реализующего нечеткие продукционные правила классификации ВОб (3-8), включает в себя такие операции и действия: выполняется автоматическая классификация ВОб (блок 1); оператор принимает решение о классификации ВОб, которые не были автоматически классифицированы (блок 3); в соответствии с принятым решением осуществляется выбор класса ВОб (блоки 10-15, 21-24) при выполнении соответствующих условий (блоки 4-9, 17-20) в соответствии с правилами классификации ВОб (формулы 3-12); результаты классификации отображаются на мониторе АРМ оператора (блок 16). 


\section{Выводы}

1. Разработана база нечетких продукционных правил нечеткой логической системы классификации воздушных объектов в процессе контроля воздушного пространства и обобщенный алгоритм реализации этих правил.

2. Структурно нечеткие продукционные правила соответствуют правилам нечеткой логической модели Сугэно 0-го порядка. Формальное представление процесса классификации воздушных объектов с использованием нечеткой логической модели позволяет учесть нестохастический и субъективный характер процесса принятия решения оператором.

3. Непосредственно обобщенный алгоритм реализации нечетких продукционных правил класси- фикации воздушных объектов включает алгоритмы решения частных задач автоматической и автоматизированной их классификации по соответствующим характеристикам на основе использования механизмов нечеткого вывода Сугэно 0-го порядка.

4. Разработан пример использования нечеткого логического вывода Сугэно 0-го порядка на базе разработанных правил.

5. Усилия, направленные на разработку базы нечетких продукционных правил нечеткой логической системы классификации воздушных объектов в процессе контроля воздушного пространства и обобщенного алгоритма реализации этих правил, послужат основой для разработки метода верификации программного обеспечения нечеткой логической системы классификации воздушных объектов.

\section{СПИСОК ЛІТЕРАТУРИ}

1. Mengshoel O. J., Delab S. Knowledge validation: principles and practice// IEEE Expert. - 1993. - 8. - P. 62 - 68.

2. Jahnke J., Schafer W., Zundorf A. Genetic fuzzy reasoning nets as a basis for reverse engineering relational database applications. - Germany, 1998.- 100 s.- http://www.unipaderbom.de/fachbereich/Schaefer/index engl.html.

3. Hasegama T., Furuhashi T., Uchikama Y. Stability analysis of fuzzy control systems based on Petri nets// Proc. Int. Discourse on Fuzzy Logic and the Management of Comflexity, FLAMOC'96. - 1996. - P. 191 - 195.

4. Polat F., Guvenir H. UVT: A unification-based tool for knowledge bast verification// IEEE Expert. - 1993. - 8. - P. 69 - 75.

5. Тимочко А.А. Представление динамических взаимодействующих процессов в пространстве состояний нечеткой раскрашенной сети Петри для верификации программного продукта нечеткой логической системы классификации / А.А. Тимочко // Наука і техніка Повітряних Сил. - Х. : ХНУПС, 2018. - №4(33). - С. 72-79.

6. Королюк Н.А. Формирование продукционных правил определения целесообразных параметров перехвата истребителями воздушных целей в условиях нестохастической неопределенности / Н.А. Королюк // Радіоелектронні і комп'ютерні системи. - Х.: НАУ «ХАІ», 2007. - №1(20). - С. 94-100.

Рецензент: д-р техн. наук, проф. М. А. Павленко, Харківський національний університет Повітряних Сил імені Івана Кожедуба, Харків Received 26.06.2018 Accepted for publication 12.09.2018

\section{Розробка бази нечітких продукційних правил нечіткої логічної системи класифікації повітряних об’єктів у процесі контролю повітряного простору й узагальненого алгоритму їх реалізації}

\section{О.О. Тімочко}

Контроль повітряного простору вимагає створення системи класифікації повітряних об'єктів. Це завдання вирішується в нечіткій постановці. Для цього розроблена база нечітких продукційних правил і узагальнений алгоритм їх реалізації. Стверджується, що традиційні підходи до розробки баз правил не досить ефективні для даної предметної області. Мета статті - розробка бази нечітких продукційних правил нечіткої логічної системи класифікації повітряних об'єктів. Проаналізовані підходи до розробки бази нечітких продукційних правил нечітких логічних систем класифікації. Для класифікації повітряного об'єкту встановлюється його приналежність до наперед заданого класу. Наперед задані класи формально задаються у вигляді множини. Елементами множини є класи, визначувані автоматично або ті, що задаються автоматизовано. Визначені основні ознаки для класифікації повітряних об'єктів. Значення ознак визначаються за результатами узагальнення трасової інформації або встановлюються за умовчанням. Значення ознак є лінгвістичними змінними. У загальному випадку вони є нечіткими числами, що описують терми відповідних лінгвістичних змінних. Структурно нечіткі продукційні правила відповідають правилам нечіткої логічної моделі Сугено 0-го порядку. Розроблений приклад використання нечіткого логічного виведення Сугено 0-го порядку на базі розроблених правил. Розроблена база нечітких продукційних правил і узагальнений алгоритм їх реалізації є основою методу верифікації програмного забезпечення нечіткої логічної системи класифікації повітряних об'єктів в процесі контролю повітряного простору.

Ключов і слов а: нечітке продукційне правило, класифікація повітряних об'єктів, база знань, функція приналежності, ознака повітряного об'єкта.

\section{Development of a fuzzy productive rules of a fuzzy logical classification system of air objects} in the air space control and generalized algorithm of their realization

\section{O. Timochko}

Airspace control requires the creation of a classification system for air objects. This problem is solved in a fuzzy setting. For this purpose, a base of fuzzy production rules and a generalized algorithm for their implementation have been developed. It is argued that traditional approaches to the development of rule bases are not sufficiently effective for the subject area under consideration. The purpose of the article is to develop a base of fuzzy production rules of a fuzzy logical system of classification of air objects. Analyzed approaches to the development of a base of fuzzy production rules of fuzzy logic classification systems. To classify an air object, its belonging to a predetermined class is established. Predefined classes are formally defined as a set. The elements of a set are classes defined automatically or set automatically. Identified the main features for the classification of air objects. The values of the signs are determined by the results of summarizing the trace information or are set by default. Character values are linguistic variables. In general, they are fuzzy numbers describing the terms of the corresponding linguistic variables. Structurally fuzzy production rules follow the rules of the 0th order fuzzy logical model of Sugeno. An example of using Sugeno 0-th order fuzzy inference based on the developed rules has been developed. The developed base of fuzzy production rules and a generalized algorithm for their implementation are the basis of the verification method for the software of a fuzzy logical system for classifying air objects in the process of monitoring airspace.

Keywords : fuzzy production rule, classification of air objects, knowledge base, membership function, sign of an air object. 